\title{
Cardiac echinococcosis: clinical picture and complications
}

\author{
F. Perez-Gomez, H. Duran, S. Tamames, J. L. Perrotef, and A. Blanes
}

From the Departments of Cardiology, Surgery, and Pathology of the Clinic Hospital of the Faculty of Medicine, Madrid; the Hospital of the Faculty of Medicine, Salamanca and Bilbao, Spain

We present 6 cases of hydatid heart disease which illustrate the different clinical pictures of this rare affection. Apart from uncomplicated forms the disease may present with valvular obstruction, acute pericarditis with tamponade, pericardial cysts, pulmonary embolism with pulmonary hypertension or systemic embolism.

Cardiac echinococcosis is extremely rare. Its incidence, even in countries where it is endemic, is less than 2 per cent of the total incidence of echinococcosis. Since the first case described by Dévé (190I) less than 100 have been reported. The diagnosis can easily be suspected and surgical treatment is simple and lifesaving if it is done before complications set in. We present 6 cases of hydatid heart disease with special reference to the clinical picture and complications.

\section{Subjects and methods}

Five men and one woman aged between 26 and 65 years were studied (Table). Clinical examination was carried out in all cases and electrocardiogram and chest $x$-rays in 5. Cardiac catheterization and angiocardiography were performed in 2. Three were treated surgically and necropsy was carried out in the other 3 ( $I$ of these had

Received 6 August 1973.

+ Deceased.

TABLE Clinical data and complications been previously operated on). Operation was performed through a left thoracotomy in 2 cases and medial sternotomy in $\mathrm{I}$. The cardiac cyst was removed in 2 patients and several pericardial cysts in I of them. On one occaion a cyst situated in the right ventricular wall was evacuated followed by formol injection.

\section{Results}

The following clinical forms of cyst were found.

\section{a) Intraparietal cyst}

The myocardium of the left ventricle was the usual site ( 3 of our cases). The progressive enlargement of the tumour produced changes in the $x$-ray appearances of the heart, best seen by tomography (Fig. I) or angiocardiography (Fig. 2). In the uncomplicated forms the patient was asymptomatic. The electrocardiogram was normal when the affected chamber was the right atrium or the right ventricle, as happened initially in our Case 4 (Fig. 3A). When the

\begin{tabular}{|c|c|c|c|c|c|c|c|c|}
\hline Case & Sex & $\begin{array}{l}\text { Age } \\
(y r)\end{array}$ & $\begin{array}{l}\text { Anaphylactic } \\
\text { reactions }\end{array}$ & $\begin{array}{l}\text { Lung } \\
\text { cysts }\end{array}$ & Electrocardiogram & Localization & Diagnosis & Complications \\
\hline $\mathbf{I}$ & $\mathbf{M}$ & 65 & No & No & $\begin{array}{l}\text { Ischaemia } \\
\text { Arrhythmias }\end{array}$ & LV & Surgery & Adams-Stokes \\
\hline 2 & $\mathbf{F}$ & 30 & Yes & No & Ischaemia & $\begin{array}{l}\mathrm{LV} \\
\text { pericardium }\end{array}$ & Surgery & None \\
\hline 3 & $\mathbf{M}$ & $4 I$ & Yes & No & Ischaemia & pericardium & $\begin{array}{l}\text { Catheterization; } \\
\text { surgery; } \\
\text { necropsy; }\end{array}$ & Anaphylactic shock \\
\hline 4 & $\mathbf{M}$ & 47 & Yes & Yes & $\begin{array}{l}\text { RVH } \\
\text { RAH }\end{array}$ & $\mathbf{R V}$ & Necropsy & $\begin{array}{l}\text { Tamponade; } \\
\text { pulm. hypertension; } \\
\text { pulm. embolism }\end{array}$ \\
\hline 5 & $\mathbf{M}$ & 42 & Yes & Yes & $\begin{array}{l}\text { RVH } \\
\text { RAH }\end{array}$ & $\mathbf{R A}$ & $\begin{array}{l}\text { Catheterization; } \\
\text { surgery }\end{array}$ & $\begin{array}{l}\text { Pulm. embolism; } \\
\text { pulm. hypertension }\end{array}$ \\
\hline 6 & $\mathbf{M}$ & 26 & No & No & Not taken & LV & Necropsy & Systemic embolism \\
\hline
\end{tabular}

RVH, right ventricular hypertrophy; RAH, right atrial hypertrophy; LV, left ventricle; $R V$, right ventricle; RA, right atrium. 


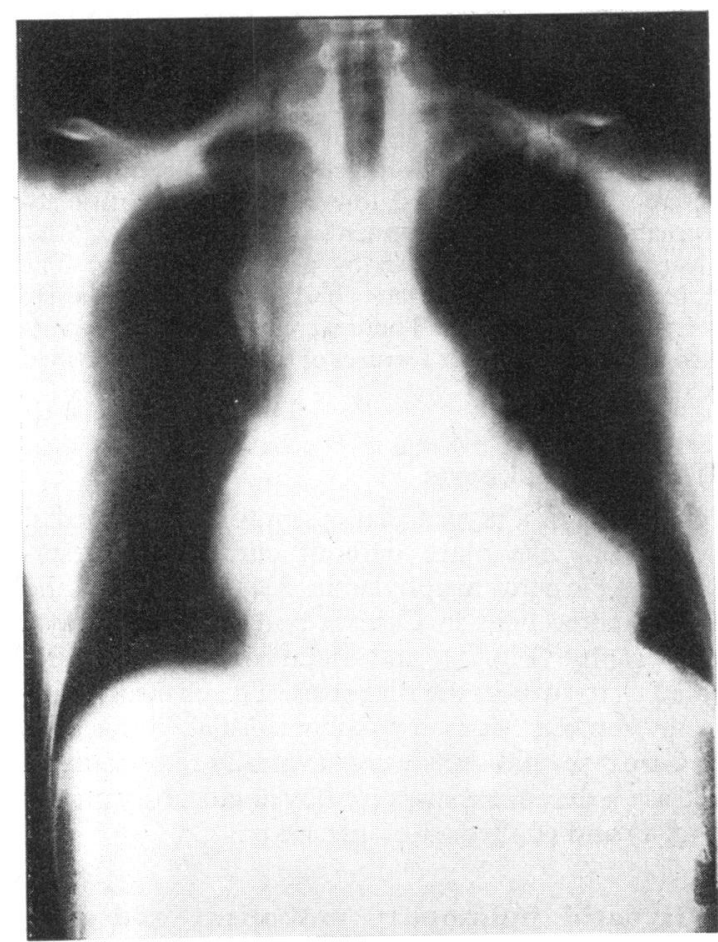

FIG. I Tomography in Case 3, showing deformities of the cardiac shadow.

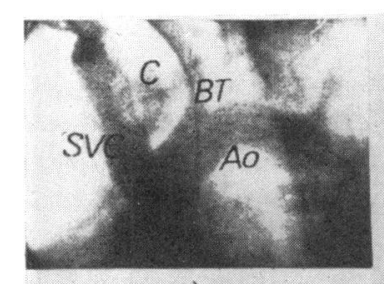

a)

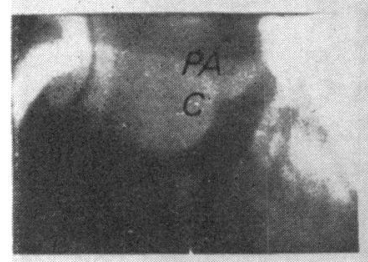

b)

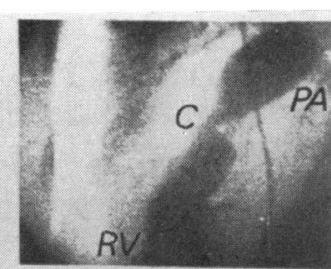

C)

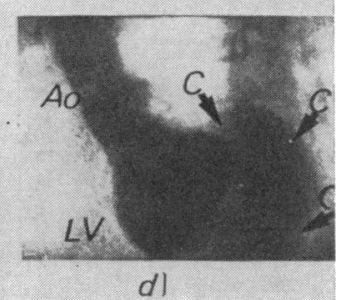

FIG. 2 Angiocardiography in Case 3. (a) Simultaneous injection into the superior vena cava (SVC) and aorta (Ao). Right ventricular angiogram in posteroanterior projection (b) and lateral (c). $R V=$ right ventricle; $P A=$ pulmonary artery. d) Left ventricular angiogram, lateral projection. $L V=$ left ventricle; $A o=$ aorta; $C=$ cysts; $B T=$ brachycephalic trunk. cyst was in the left ventricle there were signs of subepicardial ischaemia (Fig. 4). Our Case I presented with ventricular arrythmias (Fig. 4) in addition to the abnormalities of the $T$ wave, which caused episodes of Adams-Stokes syncope that responded to oral procainamide. The cysts were surgically removed without complications in Cases I and 2. In Case 5 a tumour in the right atrial wall was discovered during extirpation of a right intrapulmonary cyst a year before the patient came to us. In Cases 4 and 6 a myocardial cyst was found at necropsy with a small communication into the cardiac cavity. Finally, in Case 3, a cyst situated in the wall of the right ventricle was drained surgically.

As an example of the uncomplicated myocardial localization we present one of our two cases.

Case I A 65-year-old man, on routine chest $x$-ray was found to have a shadow deforming the left lateral edge of the cardiac silhouette. The electrocardiogram showed signs of subepicardial ischaemia in the high lateral area of the left ventricle. A cyst was removed by left thoractomy from the lateral region of the left ventricle. A few months later he presented with episodes of AdamsStokes syncope due to bouts of ventricular tachycardia (Fig. 4) that disappeared with oral procainamide.

\section{b) Valvular obstruction}

The progressive growth of a cyst situated close to a valve can narrow the valve by external compression simulating a true stenosis. An example follows.

Case 3 A 4I-year-old man had episodes of palpitation and anaphylactic reactions, some of them accompanied by syncope. On examination, the jugular venous pressure was $7 \mathrm{~cm}$ above the sternal angle with a dominant a wave. Right ventricular enlargement was discovered on palpation of the heart and by electrocardiogram and vectorcardiogram. On auscultation he had an ejection systolic murmur at the pulmonary area and wide splitting of the second heart sound. The phonocardiogram showed the pulmonary component occurring 0.05 to $0.07 \mathrm{sec}$ after the aortic. Right heart catheterization confirmed a systolic gradient of $25 \mathrm{mmHg}$ between the right ventricle and the pulmonary artery with a right ventricular systolic pressure of $45 \mathrm{mmHg}$. Angiocardiography showed a tumour within the anterior wall of the infundibulum of the right ventricle causing a narrowing of the outflow tract (Fig. 2b and c), and some cysts on the epicardial aspect of the posterolateral wall of the left ventricle (Fig. 2d), and another in the mediastinum between the superior vena cava and the ascending aorta (Fig. 2a).

\section{c) Acute pericarditis}

Acute involvement of the pericardium with massive effusion occurred in Case 4 . 


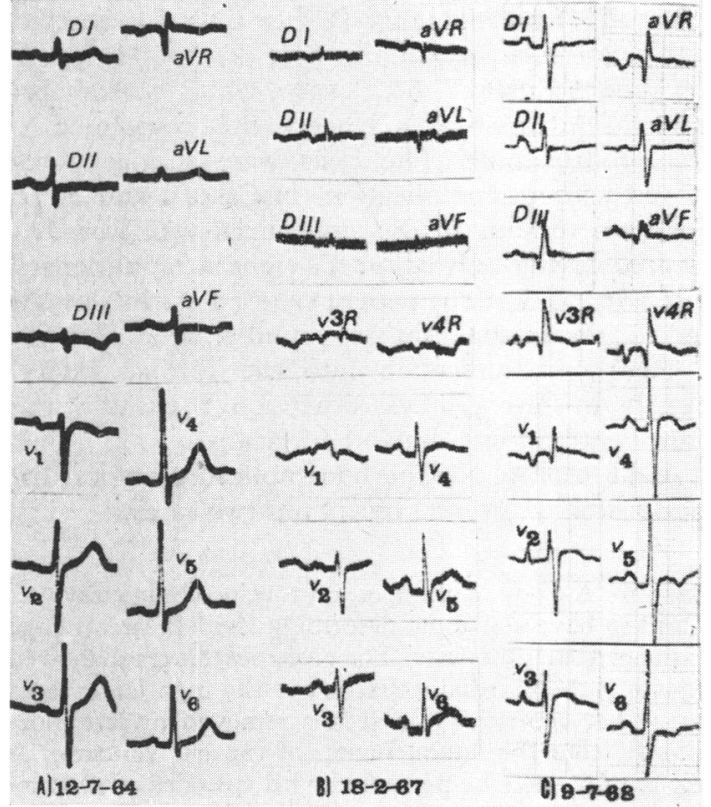

FIG. 3 Electrocardiographic evolution in Case 4. A) Normal. B) Low voltage and abnormalities of the $T$ wave. C) Right ventricular and right atrial hypertrophy.
Case 4 A 47-year-old man presented with sudden retrosternal pain and an anaphylactic reaction. A pericardial rub was heard and two days later he had signs of cardiac tamponade. Massive widening of the cardiac shadow (Fig. 5) was demonstrated radiologically and the electrocardiogram showed low voltage and diffuse abnormalities of the ST segment and T wave (Fig. 3 B). Clear fluid was withdrawn by pericardiocentesis. The patient died 14 months later, and at necropsy adhesive pericarditis was found. There were no cysts in the pericardial cavity. (Further features of this case are described below.)

\section{d) Pericardial cysts}

Perforation of a myocardial cyst into the pericardial cavity can take place without clinical manifestations. Transient anaphylactic reactions were the unique antecedent in Cases 2 and 3. Chest $x$-rays, tomography (Fig. I), and angiocardiography (Fig. 2) led us to suspect the diagnosis. The electrocardiogram showed signs of subepicardial ischaemia. In Case 2 several cysts were surgically removed and in Case 3 they were suspected by angiocardiography (Fig. 2) and confirmed by necropsy.

e) Hydatid pulmonary embolism and pulmonary hypertension

Rupture of an intramural cyst into the cavity of the

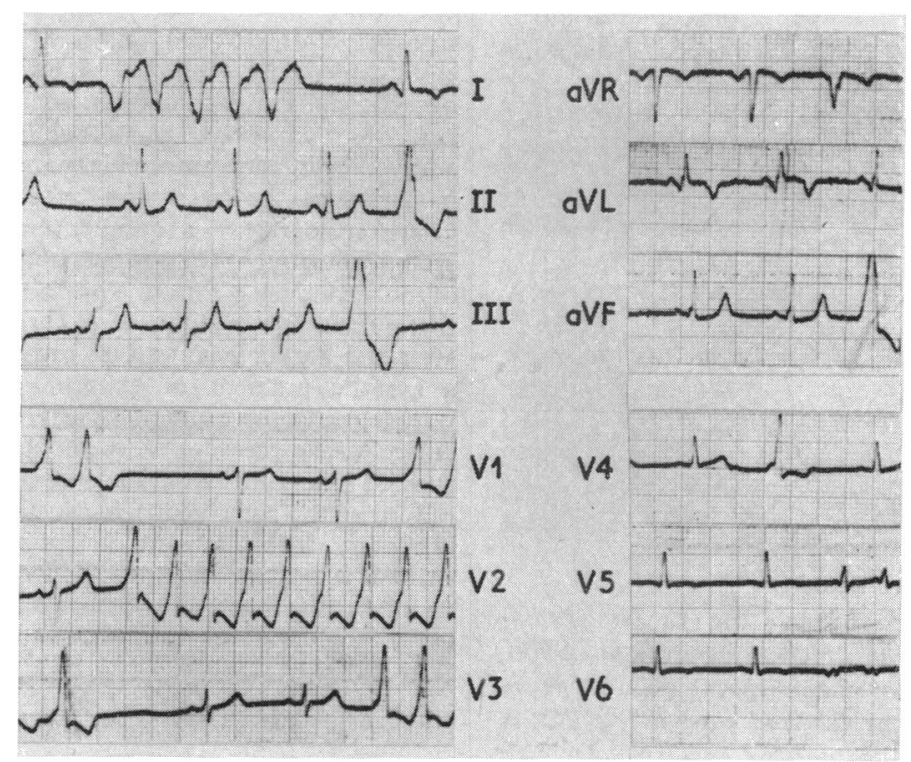

FIG. 4 Postoperative electrocardiogram in Case I. Subepicardial ischaemia and a bout of ventricular tachycardia. 
right atrium or the right ventricle enables the daughter cysts to enter the pulmonary circulation producing an acute right ventricular overload. This occurred in 2 of our patients.

Case 4 (Already mentioned above) had presented at the age of 43 with cysts in both lungs, which were removed by bilateral thoracotomy. The electrocardiogram and the cardiac shadow on chest $x$-rays were normal at that time. Three years later he developed cardiac tamponade, and 4 months later several episodes of anaphylactic crisis, breathlessness, haemoptysis, and right ventricular failure. Pulmonary hypertension was diagnosed by clinical examination (loud pulmonary sound, right ventricular hypertrophy, and right ventricular failure, evidenced by enlarged liver, raised jugular venous pressure, and generalized oedema). The electrocardiogram indicated right ventricular hypertrophy (Fig. $3 \mathrm{C}$ ) and the chest $x$-ray showed enlargement of the pulmonary arteries, areas of pulmonary infiltration, and elevation of the right diaphragm. The patient died one month after the appearance of these symptoms. At necropsy, a large cyst was found within the anterior wall of the right ventricle (Fig. 6), which was full of daughter cysts, and a small communication with the cavity. Several cysts were also found occupying the branches of the pulmonary artery, and there was organized thrombus at the origin of the left pulmonary artery, and several areas of recent infarction in both lungs.

Case 5 A 42-year-old man had had at the age of 4I, a right thoracotomy in another hospital, for pulmonary cystectomy. During the operation a tumour was seen in the right atrium but no attempt was made to remove it. He came to us with a history of severe breathlessness which had started one month after operation. He had signs of pulmonary hypertension, tricuspid incompetence, and raised jugular venous pressure. The electrocardiogram showed right ventricular hypertrophy, and the chest $x$-rays demonstrated dilatation of the pulmonary artery, its main branches, and the right ventricle. The films also showed several lung cysts. At cardiac catheterization the following pressures $(\mathrm{mmHg}$ ) were found: pulmonary artery 104/45, femoral artery $102 / 70$,

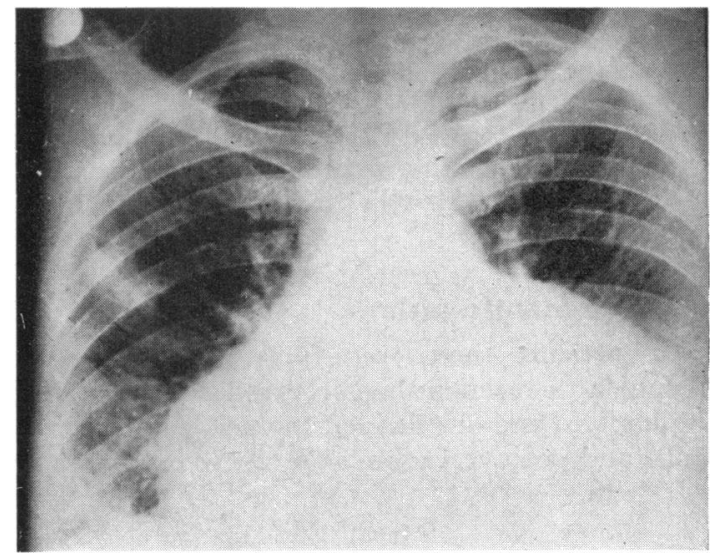

FIG. 5 Chest $\mathrm{x}$-ray in Case 4. Massive pericardial effusion.

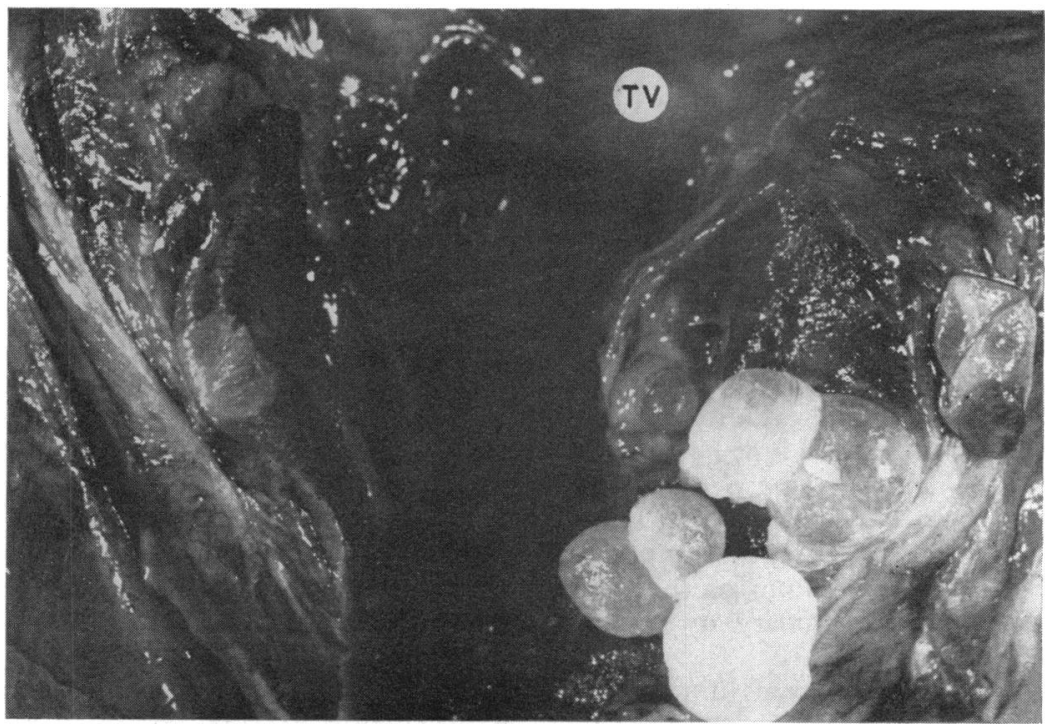

FIG. 6 Opened right ventricle. Several daughter cysts entering the cavity of the ventricle. 
right ventricle $104 / 5$ with an end-diastolic of 30 , mean right atrium 20. Angiography of the pulmonary arteries disclosed several intraluminal filling defects. The patient died at home some days later and there was no necropsy.

\section{f) Systemic embolism}

A cyst located in the wall of the left side of the heart which communicates with the cavity may be the origin of systemic embolism, usually to the brain. The following case is an example.

Case 6 A 26-year-old man had had epileptic fits for the previous 6 years. He recently developed a transient right hemiparesis. Cerebral angiography and pneumoencephalography revealed no abnormal findings. A sudden right hemiplegia developed leading to deep coma and death. Necropsy disclosed a large cyst in the wall of the left ventricle, communicating with the cavity. Several small cysts were also found within the ateries of the brain and kidneys.

\section{g) Other manifestations}

In 2 patients there were previous lung cysts. Anaphylactic reactions had occurred in 4. Three had palpitations, and one had left thoracic pain. Eosinophilia and positive Casoni skin test were present in 4 of them.

\section{Discussion}

Hydatid cyst of the heart has special characteristics caused by difficulties in its growth. The kinetic pressure of the heart increases the tension around the cyst shortening its life span and favouring the likelihood of its rupture into the heart or pericardium (Dévé, 1946).

The natural history of hydatid heart disease usually follows three stages: I) The embryo arrives into the myocardium via the coronary circulation. Coming from the intestine and passing either across the liver or along the azygos veins it first reaches the right atrium. From there it may get to the left heart and the coronary arteries either through the foramen ovale or crossing the pulmonary filter. The scolex, which is also able to germinate, may come from an adult hepatic cyst following the previously described pathways or from the rupture of a lung cyst into the pulmonary veins. 2) The developing period within the myocardium is from $I$ to 5 years and during this time it may calcify and die, or grow in situ. 3) It may perforate into the pericardium or the cavity of the heart originating pulmonary or systemic embolism.

The electrocardiogram is normal in uncomplicated cases, when the cyst is located in the right side of the heart. However, when the cysts are in the left ventricle or in the pericardium the patients usually show signs of subepicardial ischaemia and occasionally abnormal $Q$ waves.

The growth of a cyst situated close to a valve may cause obstruction (Bulnheim, 1890; Artucio et al., 1962), leading to murmurs and pressure gradients, as was seen in one of our cases (Case 3). Cardiac catheterization and angiocardiography are both helpful in making the diagnosis. Coronary arteriography will show the arteries displaced by the tumour (Rivera, Lazaro, and Delcan, 1970).

A cyst located in the right side of the heart in communication with the cavity permits the entry of daughter cysts into the pulmonary circulation causing obstruction of the arteries. The rupture of a hepatic cyst into the inferior vena cava or the hepatic veins may cause the same clinical picture, but it is uncommon; Purriel et al. (1970) found only I4 published cases. A different clinical picture may appear, depending on the size of the embolus: I) Acute lethal form: 2) subacute pulmonary hypertension leading to right ventricular failure and death in less than I year; Cases 4 and 5 may be included in this group: 3) chronic pulmonary hypertension caused by repeated small emboli, giving no symptoms, except for occasional bronchospasm. The patients develop intractable right ventricular failure and die after a period of several months or years. This is the most common form, according to Purriel et al. (1970).

The prognosis of hydatid pulmonary hypertension is poor. To our knowledge, only one published case, submitted to early operation, survived (Artucio et al., 1962).

According to Garnier and Jomier (1905) and Purriel et al. (1970), thrombosis secondary to hydatid pulmonary embolism, is rare, but it has been previously found (Dévé, 1915) and we have an example in Case 4.

Complications involving the pericardium are of three types: a) Silent rupture with appearance of adult cysts some months later (Starr, 1949; Molloy, 1955; Tountas, 1957); Cases 2 and 3 are examples of this possibility: b) Acute pericarditis with or without cardiac tamponade, as occurred in Case 4: c) Constrictive pericarditis as described by Larghero, Di Bello, and Victoria (1950) and Di Bello (1970).

Mediastinal hydatid disease is rare. It was reported by Rakower and Milwidsky (1960), and we found it in Case 3, who had a cyst between the ascending aorta and the superior vena cava.

Surgery consists in the removal of the cyst by means of simple thoracotomy when it is located in the epicardium (Gibson, 1964). When it is large and deeply placed, removal cannot be done without extracorporeal circulation (Rivera et al., 1970). In any 
case, it is important to make an early diagnosis and to perform surgery before complications occur.

Our thanks are given to Dr. Caro Paton for sending us Case 2, to Professor Merchante for referring Case 3, and to Dr. Wallace Brigden and for helpful criticism and corrections.

\section{References}

Artucio, H., Roglia, J. L., Di Bello, R., Dubra, J., Gorlero, A., Polero, J., and Urioste, H. A. (1962). Hydatic cyst of the interventricular septum of the heart with rupture into the right ventricle. Fournal of Thoracic and Cardiovascular Surgery, 44, 110.

Bulnheim, K. (1890). Ein Fall von Echinococcus-embolie der Hirnarterien. C. Böckel, Kiel.

Dévé, F. (1901). De l'echinococcose secondaire embolique. Comptes Rendus des Séances de la Société de Biologie et de ses Filiales, 53, 608.

Dévé, F. (1915). Sur l'echinococcose secondaire du péricarde. Comptes Rendus des Séances de la Société de Biologie et de ses Filiales, 78, 734.

Dévé, F. (1946). L'echinococcose Secondaire. Mason et Cie, Paris.
Di Bello, R. (1970). Hydatid constrictive pericarditis. fournal of Thoracic and Cardiovascular Surgery, 59, 530.

Garnier, M., and Jomier, J. (1905). Des embolies hydatiques de l'artère pulmonaire. Presse Médicale, 13, 369.

Gibson, D. S. (1964). Cardiac hidatid cysts. Thorax, 19, 15 I.

Larghero, P., Di Bello, R., and Victoria, A. (1950). Hydatidic constrictive pericarditis. Archivos Internacionales de la Hidatidosis, 11, 346.

Molloy, P. J. (1955). Pericardial hydatid cysts. New Zealand Medical fournal, 54, 267.

Purriel, P., Tomalino, D., Muras, O., and Acosta Ferreira, W. (1970). Embolismo pulmonar hidático. Tórax, 19, 164

Rakower, J., and Milwidsky, H. (1960). Primary mediastinal echinococcosis. American fournal of Medicine, 29, 73.

Rivera, R., Lazaro, P., and Delcan, J. L. (1970). Hidatidosis cardiaca: tratamiento quirúrgico bajo circulación extracorpórea. Sevilla Medica, 2, 15.

Starr, K. W. (1949). Hydatid cyst of the pericardium. Australian and New Zealand fournal of Surgery, 18, 342.

Tountas, C. (1957). Le kyste hydatique du péricarde. Archivos Internacionales de la Hidatidosis, 16, 419.

Requests for reprints to Dr. F. Perez-Gomez, Departmento Central de Exploracion Cardiopulmonar, Facultad de Medicina, Hospital Clinico de San Carlos, Madrid-3, Spain. 